\title{
28 Research Square \\ In-planta Agrobacterium-mediated Stable hva1 and EPSPS Integration into Potato var. Agria Genome
}

\section{Darush Choobineh}

University of Zabol

nafiseh mahdi nezhad ( $\nabla$ nmahdinezhad@uoz.ac.ir)

University of Zabol https://orcid.org/0000-0002-0582-9227

Ali Niazi Niazi

Shiraz University School of Agriculture

\section{Baratali Fakheri}

University of Zabol

Abbasali Emamjomeh

University of Zabol

\section{Research article}

Keywords: Potato, Solanum tuberosum, Transgene, In-planta, Agrobacterium tumefaciens, hva1, EPSPS

Posted Date: September 21st, 2021

DOI: https://doi.org/10.21203/rs.3.rs-916523/v1

License: (c) (1) This work is licensed under a Creative Commons Attribution 4.0 International License. Read Full License 


\section{Abstract}

\section{Background}

After wheat, maize, and rice, potato is not only an important food crop but also a substantial source of income throughout the world. Developing a practical and effective transformation method for cultivars that are recalcitrant in tissue culture is vital. Hva 1 encodes the protein of the LEA III superfamily that involves in reactions to abiotic stresses, which holds considerable potential for use as molecular tools for genetic crop improvement toward stress tolerance.

\section{Results}

Here, a protocol has been designed for an Agrobacterium-mediated transient transformation in tissue culture-independent conditions in-planta. The protocol establishes for hva 1 and EPSPS transformations by direct injection of the bacterial suspension into the potato tuber sprout to encode resistance to cold and against glyphosate herbicide. A two-stage selection was involved using $1 \%$ and $2 \%$ Glyphosate to eliminate the chimeric and non-transformed plants. Ultimately, the protocol enabled confirmation of gene integration into the plant, transgene expression of the gene and transgene expression, which was made possible by competitive PCR reaction, RT-PCR, and ELISA, respectively. In this research, the transformation efficiencies acquired in potatoes (up to $46 \%$ ) were higher than those reported using conventional Agrobacterium-mediated approaches in previous studies.

\section{Conclusions}

The constitutive expression of the integrated T-DNA neither slowed down the growth rate nor affected potato tuberization significantly. The hva 1 gene was expressed successfully leading to the accumulation of the hva1 protein in transgene-generated tubers. This study is the first report on a successful transformation of potato in-planta whereby Agrobacterium can be directed at potato seed sprouts through injection.

\section{Background}

Potato (Solanum tuberosum L.) is a traditional crop plant that serves as an essential part of many diets in different human populations. At present, it is an important food crop (the fourth most important after wheat, maize, and rice), which is grown in more than 100 countries [1]. However, the Andes Mountains on the border between Bolivia and Peru in the west of South America is regarded widely as the primary center where potatoes originated from [2-3]. From an industrial viewpoint, potato is a common source for the manufacturing of starch, alcoholic drinks, and other processed products like French fries and crisps. Although potatoes contain relatively little protein content, they are a nonfattening, nutritious, and wholesome food. Their nutritional quality is sometimes superior in comparison with cereals [3-4]. 
The common potato is an autotetraploid plant with four sets of similar chromosomes $(2 n=4 x=48 ; n=$ 12). It is highly heterozygous and, thus, breeding for biotic and abiotic tolerance is difficult by conventional means [5]. Therefore, countering the damages caused by biotic/abiotic stresses requires other advanced tools such as genetic manipulation for producing potato cultivars that are resistant to biotic/abiotic stresses. Meanwhile, such advanced techniques can assist in improving potato yield, tuber quality, and market value [6]. In this regard, various transformational techniques have been designed, including but not limited to particle bombardment [7], microinjection [8], and Agrobacterium-mediated methods [2, 9-11]. The latter technique involves incorporating foreign genes into potato cells, followed by a stable establishment of the genes. However, efforts have been made with various degrees of success because the mechanisms of tolerance to abiotic/biotic stress are complex.

Incorporating hva1 into barely was considered successful in transgenic plants, making them tolerant to abiotic stress [12-16]. The gene encodes the protein characterized by 11-amino-acid tandem repeats (TAQAAKEKAGE). Initially, it was described in cotton as a highly accumulated protein in embryos at the late stage of seed development [17]. Then, it is hypothesized that the protein is usefully involved in bringing tolerance to abiotic types of stress like cold temperatures, frequent drought, and high salinity in different plant species $[16,18-20]$. The available literature indicates that genetic engineering can expand the potential usefulness of hva 1 as a potent molecular tool that can assist in generating plants, which as a result, become tolerant to abiotic stress $[12,13,21,22]$. Hva1 belongs to the late embryogenesis abundant protein (LEA) superfamily $[14,23]$.

Biotechnological approaches have been successfully used to transfer genes conferring herbicide resistance in crops. 5-enolpyruvylshikimate-3-phosphate synthase (EPSPS) prevents glyphosate from binding, thus allowing the resistant EPSPS to catalyze the amino acid synthesis reaction. The coding region from the bacterial EPSPS gene has been cloned and transferred to the crop plants like cotton, maize and soybean $[24,25]$. Plants expressing the EPSPS gene can be sprayed with glyphosate as they have back up enzyme that gives them the ability to keep making amino acids and are thus resistance to glyphosate [26]. There are numerous reports about the transformation of the EPSPS gene into the potato $[27,28]$.

Agrobacterium-mediated transformation is characterized by stable insertion, with a reduced copy number of transgenes and permanent expression of transgenes. Despite its advantages, tissue culture-based transformations can lead to somaclonal variation during in vitro culture and regeneration systems [29]. Somaclonal variation usually affects plant features, not only qualitatively but also quantitatively. Furthermore, agrobacterium-mediated transformation can be susceptible to fungal contamination, is time-consuming, and is sometimes expensive. Also, several lines of evidence suggest that the method cannot work for recalcitrant plants [30]. Agrobacterium-mediated transformation outside the tissue culture environment is called in-planta [31]. It can eliminate the problems associated with tissue culture and regeneration. By in-planta transformation, transgenes are introduced directly into intact plant tissues. It is efficient, fast, and simple for stable integration of foreign genes into plant genomes, as compared to transformation methods based on tissue culture. Also, it is free from somaclonal variation [32-33]. 
According to previous reports, the efficiency of in-planta transformation is much higher than that of the conventional transformation method [34]. The main advantage of the in-planta method is the production of many transgenic lines in a short period [32]. However, chimeric tissues can generate in transgenic plants, and a lack of stable transgene expression can happen by the in-planta method, although these problems can be alleviated by employing an efficient selection system [35]. More recently, alternative inplanta methods have developed in several plant species [36-40]. According to previous researches, the transformation of plants by the in-planta method has involved the direct insertion of transgenes into the germinating seeds of several plants. They consist of radish, wheat, rice, cotton, Brassica napus, floral buds of Arabidopsis, shoot apical node of alfalfa, epicotyl segments of citrus, a mature embryo of rice, fruit injection of tomato, the floral dip of Arabidopsis, Medicago truncatula, radish and wheat, pistol dip of maize, cotton, and peanut. Also, the method has been used in soybean through its pollen tube pathway $[35,41]$. Nevertheless, there has been no report on the in-planta transformation of Solanum tuberosum.

To overcome the transformation limitation of potato through tissue culture-based regeneration and to take advantage of the in-planta method, we established an in-planta Agrobacterium-mediated transformation protocol for hva1 transformation by direct injection of bacterial suspension into potato tuber sprouts. Competitive PCR reaction, Reverse Transcriptase PCR (RT-PCR), and Enzyme-Linked Immunosorbent Assay (ELISA) were carried out to confirm the integration of the gene into potato plants, the overexpression of the gene, and transgene expression. We also evaluated the effects of the integrated hva 1-harboring genetic material expression on plant growth characteristics, along with tuberization, and on improvements in plant tolerance to freeze-stress.

\section{Methods}

\section{Plant material, transformation and generation of transgenes}

In this study, we used the variety Agria (the predominant cultivated variety in Iran) which based on their previously classed as both frost and drought sensitive [42, 43]. Agria seed and tuber was obtained from Seed and Plant Improvement Institute (SPII), Karaj. To remove possible viral infections, the seeds were treated following a procedure used by Kaiser [44]. Then, the seed surface was disinfected by immersion in $0.5 \%$ hypochlorite sodium ( $\mathrm{NaClO}$ ) for $10 \mathrm{~min}$ before being rinsed and washed thoroughly in sterile distilled water thrice. The seeds were rinsed in a laminar airflow cabinet and for further use placed on an aseptic blotting paper in the disinfected dishes. To encourage the germination of potato seed sprouts, the seeds were placed in darkness at $25 \pm 2^{\circ} \mathrm{C}$ and $80 \%$ relative humidity in a growth chamber. To activate the vir gene, when the sprouts grew about 4 to $6 \mathrm{~mm}$ in length, the Agrobacterium tumefaciens cell pellet was suspended in an autoclaved MS medium (0.5 X) containing Acetosyringone $(50 \mu \mathrm{M})$. Cell suspensions were adjusted to an optical density of 1 at $600 \mathrm{~nm}(\mathrm{OD} 600=1)$. Then, the suspension was drawn into a $1 \mathrm{ml}$ insulin syringe, and the sprouts (slightly below the tip) received injections under a binocular microscope without rupturing. There were three control treatments planned as a negative control, the injected sprouts with MS medium and without Acetosyringone content as well as non-injected sprouts. The injections were renewed three times at 24 -hour intervals. Then, the seeds were stored at $25 \pm 2^{\circ} \mathrm{C}$ in 
darkness at $80 \%$ relative humidity for $48 \mathrm{~h}$ in the growth chamber. The seeds were sown in pots containing autoclaved peat moss and were grown in a greenhouse. In total, 50 replicates were set up for each injected (with Acetosyringone and without Acetosyringone treatments) and control treatments (Figure 1).

\section{Plasmid construct and Agrobacterium strain}

The hva1 gene sequence originated from Hordeum vulgare. It was obtained from the gene database of NCBI (X78205.1 access number including 1804nt). The sequence was optimized based on the potato codon-usage preference table using Gene Designer Gene2 software. Then, the Kozak and His-tag sequences were designed upstream of the hva1 coding sequence, and the KDEL (endoplasmic reticulum transmitter facilitator) was added to downstream hva 1 coded protein for proper protein folding. A sequence-specific primer for the gene coupling was designed and synthesized via Vector NTI software. Also, at the 5' head, each of the two nucleotides was designed as an enzyme sitting site. For a long-term reproduction and preservation of the structure, it was initially shifted to the $E$. coli PUC57 vector and cloned. Then, the plasmid was extracted from E. coli, and the hva 1-harboring plasmid PUC57 vector was performed in association with Sacl and BamHI enzymes, and the hva1-containing structure was released. For the structural transformation, a modified pBI121 binary plasmid expression vector served as a carrier. The vector consisted of a $1.4 \mathrm{~kb}$ DNA fragment containing 5-enolpyruvylshikimate-3-phosphate synthase (EPSPS, A Glyphosate-resistant gene) as a plant-selection-marker. The gene cassette was cloned in the plant expression vector, being under the expressional control of an enhanced 35S promoter from the cauliflower mosaic virus (CaMV). From then on, the expression carrier was called hva 1-pBI121 (Supplementary file 1).

SaCl and Kpnl enzymes were applied to confirm the presence of hva 1 in the structure. The enzymes cut the plasmid at the relevant designed restriction sites and relaxed the 10091 and 3938 bp segments, which confirmed the presence of EPSPS in the complex. Also, colony PCR of the structure was carried out to confirm the presence of hva 1 in the complex. Furthermore, to confirm the existence of hva 1 in the vector, enzymatic digestion was performed using Sacl and Kpnl enzymes (the Kpnl cleavage site is in the middle of the EPSPS gene, which is not naturally present in $\mathrm{pBI}$ and confirms the presence of EPSPS in the structure).

Agrobacterium tumefaciens strain C58 contained the binary vector hva1-pBI121. This strain was used as

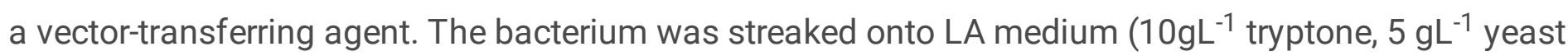
exact and $5 \mathrm{gL}^{-1} \mathrm{NaCl}$, and Agar $7 \mathrm{gL}^{-1}$ ), which had been supplemented with 50 mg Kanamycin and 50mg Rifampicin. Then, an individual colony was randomly sampled from the culture and re-cultured in a modified LB medium (containing 50 mgL-1 Rifampicin $50 \mathrm{mgL}^{-1}$ Kanamycin). Then, the culture was incubated in the growth chamber for $48 \mathrm{~h}$ at $28^{\circ} \mathrm{C} \pm 1$ on a rotary (at $135 \mathrm{rpm}$ ) in dark conditions to form homologous colonies (OD600=0.3). The explants were treated with $A$. tumefaciens cell pellets in an autoclaved MS medium ( $0.5 \mathrm{X})$ containing Acetosyringone $(50 \mu \mathrm{M})$. This was to achieve a higher transformation efficiency. To study the effects of Acetosyringone content on the efficacy of the 
transformation, the explants were also treated by $A$. tumefaciens cell pellets in MS medium with no Acetosyringone, which served as the control.

\section{Glyphosate lethal concentration and Glyphosate screening of putative transformants}

To evaluate the Glyphosate lethal concentration in transgenic and non-transgenic potatoes, the experiment was designed in two groups of transgenic and non-transgenic potato plants by five Glyphosate dosages $(0 \%, 0.25 \%, 0.5 \%, 1 \%$, and $2 \% \mathrm{v} / \mathrm{v})$ in four replicates for each treatment. Potato tubers were placed in pots and stored in the greenhouse at $20-30{ }^{\circ} \mathrm{C}$ while receiving $16 / 8 \mathrm{hr}$ day $/ \mathrm{night}$ light. The plants were watered every seven days. When the plantlets had grown $15-30 \mathrm{~cm}$ tall, they were sprayed thoroughly with the Glyphosate solution in $\mathrm{ddH} 2 \mathrm{O}$. Morphological changes of the treatment were considered in comparison with the control. The changes were monitored at intervals of one, two, three, and four weeks after the treatment. Necrotic lesions were considered and the damage was reported in percentages (Compared to healthy tissues). Statistical significance was determined by one-way analysis of variance (ANOVAs) and by Tukey's Multiple Comparison test $(\mathrm{P} \leq 0.05)$.

In this study, we used the EPSPS as a marker to distinguish transformants from non-transformants. Also, for eliminating chimeric plants, the two-stage selection was performed with 1 and $2 \%$ V/V Glyphosate concentration respectively and monitored for the foliage tolerate. The transformants, which tolerated the Glyphosate treatments and continued to survive, were selected for further experiments. Non-transformed plants and the control group either achieved no growth or died.

\section{PCR- mediated confirmation of putative transformants}

The genomic DNA was extracted carefully from the leaves of treated plants according to the method of Cetyl Trimethyl Ammonium Bromide (CTAB) extraction, as modified by Gawel and Jarret (1991). Purified DNA was stored in TE buffer at $-20^{\circ} \mathrm{C}$ for further use. The standard Polymerase Chain Reaction (PCR) for

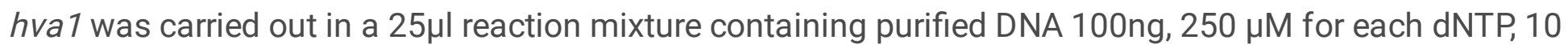
pM of hva 1 specific designed primers (Forward primer 5'-ACACTTCTGATACACCTTTC-3' and Reverse primer 5'-GTTACCATTTCCCACACC-3'), 2mM MgCl2, 1.25 U Taq DNA polymerase and Taq buffer. The reaction mixture in the tubes was placed in a programmable thermal cycler model MJ research PTC-200. The thermal cycler was programmed as follows: setting an initial denaturation at $94^{\circ} \mathrm{C}$ for $5 \mathrm{~min}, 30$ amplification cycles (denaturalizing at $94^{\circ} \mathrm{C}$ for $45 \mathrm{~s}$, annealing at $60^{\circ} \mathrm{C}$ for $30 \mathrm{~s}$ and extension at $72^{\circ} \mathrm{C}$ for $20 \mathrm{~s}$ ). Then, a final extension was performed at $72^{\circ} \mathrm{C}$ for $10 \mathrm{~min}$. Also, the PCR reaction was performed on $20 \mu \mathrm{l}$ reaction mixtures containing 100ng purified DNA, $250 \mu \mathrm{M}$ of each dNTP, 10 pM EPSPS specific primers (while the sequences of the primers were as follows: forward primer 5'-TTGGTTGTCAGAGGTAGA-3' and Reverse primer 5'-AGCAGCCTTAGTATCAGA-3'), and 0.75 U Taq DNA polymerase for amplification of EPSPS sequence and verification. The PCR reaction program began at $94^{\circ} \mathrm{C}$ for 4 min to allow an initial denaturation, followed by 30 amplification cycles (for 45 s to allow denaturation at $94^{\circ} \mathrm{C}, 30$ s of annealing at $60^{\circ} \mathrm{C}$ and 20 s of extension at $72^{\circ} \mathrm{C}$ ). A final extension was applied at $72^{\circ} \mathrm{C}$ for 30 s. Also, a PCR was carried out using the virG specific primers (C58F; $5^{\prime}$ ITACGCAGCAGGTCTCAT-3' and C58R; 5'-CGAAGGATAGTGGGATTGTG-3') on putative transgenic lines. 
This was to detect contamination with Agrobacterium and to confirm the integration of the structure into the plant genome, exactly one month after injection. All PCR-tested samples were separated on $2 \% \mathrm{TAE}-$ buffered agarose gels, stained with ethidium bromide $(0.5 \mu \mathrm{g} / \mathrm{ml})$ for $20 \mathrm{~min}$, and visualized with UV illumination. No specific fragment was amplified on putative transgenic lines, which shows that the lines weren't contaminated with Agrobacterium (GeneRuler DNA Ladder Mix).

\section{Semi-Quantitative Reverse Transcription (RT)-PCR}

The total RNA was extracted from the leaves of both positive PCR-tested transformants and control plants by an RNA extraction kit (DENAzist Ltd. IRAN). The contaminating DNA was removed by a DNasel DNase Kit. Then, the elimination of DNA contamination was confirmed by the absence of bands on the gel. The transgene expression was confirmed by carrying out RT-PCR. The DNase-treated extracted RNA was converted initially to complementary DNA (cDNA) using $1 \mu$ g total RNA in a $20 \mu$ l RT-reaction containing oligo dT as a primer and RevertAid enzyme. The reaction mixture was subjected to denaturation at $65^{\circ} \mathrm{C}$ for 5 min before cooling down to $37^{\circ} \mathrm{C}$. Then, $40 \mathrm{U}$ of M-MuLV entered the reaction mixture allowing an extension at $37^{\circ} \mathrm{C}$ for $1 \mathrm{~h}$, but which later was stopped by being heated at $70^{\circ} \mathrm{C}$ for $10 \mathrm{~min}$. Subsequently, $20 \mu \mathrm{l}$ of the cDNA was used as a template for an exponential amplification reaction using $n p t / l$ primers (Forward, 5'-AGATCCCGTGGGCGAAGAACT-3' and Reverse, 5'-

GGATCGTTTCGCATGATTGAA-3'). The reaction mixture contained 1× PCR buffer, $50 \mathrm{ng}$ cDNA template, 1 pmol of each primer and $2 \mathrm{U}$ of Taq DNA polymerase. Thirty PCR amplification reaction cycles (causing denaturation at $94^{\circ} \mathrm{C}$ for $30 \mathrm{~s}$, annealing at $65^{\circ} \mathrm{C}$ for $30 \mathrm{~s}$ and extension at $72^{\circ} \mathrm{C}$ for $1 \mathrm{~min}$ ) were performed after an initial denaturation condition at $94^{\circ} \mathrm{C}$ for $5 \mathrm{~min}$, followed by a final elongation at $72^{\circ} \mathrm{C}$ for 8 min. Also, RT-PCR for hva 1 and EPSPS was carried out when appropriate. The PCR products were separated by $1 \%$ agarose gel electrophoresis.

\section{Crude protein extraction and Enzyme-linked immunosorbent assay (ELISA) test}

At this stage of the experiment, all the positive PCR-tested transformants were considered for extracting total crude protein from their young leaves. The samples in four replicates were ground under liquid nitrogen and the powder was suspended in 1:1 phosphate buffer $(100 \mathrm{mM}, \mathrm{pH}=7) \mathrm{w} / \mathrm{v}$. Then, the supernatant was prepared by centrifuging at $12000 \times \mathrm{g}$ for $10 \mathrm{~min}$ at $4^{\circ} \mathrm{C}$. The protein concentration was determined by the Bradford method (Kruger 2009) and the proteins were stored at $-20^{\circ} \mathrm{C}$ before use. ELISA was conducted with anti-His-tag polyclonal IgG according to the manufacturer's instructions (Biolegend, USA). After $45 \mathrm{~min}$ of incubation with in the substrate, the absorbance was measured at $450 \mathrm{~nm}$ using an ELISA reader. Two controls (Bovine serum albumin (BSA) and the non-treated plant samples) were set in this experiment. Four replicates were set for each treatment. The results were confirmed by repeating the experiment thrice. The differences between the control group and the test samples were analyzed by oneway analysis of variance (ANOVAs) and by Tukey's Multiple Comparison Test. A $P$-value of less than 0.05 was set as statistical significance.

Effect of the integrated genetic material expression on plant growth and tuberization 
The expression of integrated genetic material may affect the plant growth and tuber formation. These were examined by comparing the phenotypes of the control plants with the transgenic plants grown in the greenhouse for ten weeks. The plant weight, height, number of potato tubers and physical appearance were considered. The experiment was a completely randomized design (CRD) in eight replicates for each transgenic and non-treated plant. Statistical significance was determined using the one-way analysis of variance (ANOVAs) and by Tukey's Multiple Comparison test $(P \leq 0.05)$.

\section{Stability of the transgene in tubers}

The stability and expression of the transgene in the tubers were also considered. The results were analyzed based on the presence or absence of amplified PCR products (the hva 1 and EPSPS producing bond) and ELISA with anti-His-tag polyclonal IgG in the PCR-positive transgene being generated in tubers and shoots.

\section{Whole plant freezing stress treatment}

To determine how tolerant transgenic plants are to freezing stress, eight-week-old plants were placed in a growth chamber at $25 \pm 1^{\circ} \mathrm{C}$ and at $100 \mu \mathrm{mol} / \mathrm{m} 2 \mathrm{~s}$ light intensity. Then, they were exposed to $-4^{\circ} \mathrm{C}$ for $12 \mathrm{~h}$. Following the freezing treatment, they were returned to natural conditions for two weeks in order to recover. Transgenic potato tolerance was assessed by analyzing plant survival compared to nontransgenic potatoes as the control. For each transgenic and non-transgenic potato group, six replicates were grown in a growth chamber and were exposed to freezing temperatures.

\section{Results}

\section{In-planta transformation}

Here, the designed construct structure was generated, shifted to the E. coli PUC57 vector, and cloned successfully. The plasmid-harboring hva1 gene was extracted successfully from the PUC57 vector (Figure 2), and inserted into the pBI121 EPSPS-containing vector as a carrier for the structure (hva 1-pBI121).

Then, the carrier vector was cloned in E. coli after being introduced to the Agrobacterium (Figure 3).

Fifty treated tubers were transformed successfully with the hva1-pBI121 construct by the mentioned inplanta method.

\section{Glyphosate experiment}

The integration of the gene in the plant was initially analyzed by the direct application of Glyphosate on the foliage of the transplants (Figure 4).

Transgenic Glyphosate-tolerant plants that overproduced EPSPS survived even at unusual concentrations of Glyphosate (2\%). At this stage, the rate of initial screening was found to be $46 \%$ ( 23 treated plants out of 50 survived). Plant growth and tuber formation gradually decreased as the concentration of 
Glyphosate increased. Also, it was observed that treating the explants with Agrobacterium, without the presence of Acetosyringone did not lead to transformed plants, and the potatoes along with the controls died at the Glyphosate selection stage.

\section{Expression analysis}

To confirm the stable transformation of the transgenes in the potato genome, DNA were isolated from the supposed transformants after the plantlets were established. All putatively transformed plants were checked for hva 1, EPSPS, and virG using their specific primers separately. The primers amplified this gene and not the whole cassette, indicating the presence or absence of the transgene. PCR analysis revealed that from 23 Glyphosate selected potatoes, 18 transformed plants displayed approximately $190 \mathrm{bp}$ (for hva1) and $300 \mathrm{bp}$ size bands (for EPSPS). Primer sets were designed to represent positive control. They showed an appropriate bandage after PCR amplification. However, the genomic DNA from nontransformed control explants did not show any band in the PCR reaction (Figure 5).

PCR with virG specific primers did not reveal specific amplified fragments (Figure 6), which shows that the lines were not contaminated with Agrobacterium and that the bonds from hva 1 and the EPSPSPCR amplified products resulted from the integration of the structure in the plant genome. The results are indicative of stable integration of the genomic cassette into the potato genome.

The PCR failed to suggest anything about the expression level of the transgene. Therefore, the expression profile of the hva 1 and EPSPS in PCR-positive potato plantlets was analyzed by RT-PCR. The results revealed that the hva1 and EPSPS were expressed typically in PCR-positive transformants, while no detectable expression was observed for the genes in the control plantlets (Figure 7).

\section{ELISA assay for quantifying to hva1 product}

The protein expression profiling of hva1 protein in putatively transgenic plants was examined through ELISA, specific to the His-tag recombinant protein and able to confirm the expression of the His-tag gene. $O D$ values from transgenic potato plants were significantly $(P \leq 0.05)$ higher than those of the nontransgenic control plants and BSA (Figure 8).

An analysis of the recorded OD values by the ELISA reader demonstrated that transgenic plants accumulated more protein His-tag as evidenced by a higher absorbance value. However, no accumulation of His-tag protein was observed in the non-transgenic control group, thereby indicating the expression of biologically active hva1 protein in its endogenous form. ELISA results are also indicative of His-tag protein accumulation in the transgene-generated tubers but it was not significantly different. This result confirms the successful presentation of hva 1 and the hva1 protein accumulation in the transgenegenerated tuber (Figure 9).

Furthermore, the constitutive expression of the integrated plasmid neither led to growth retardation $(P=0.9152$ for plant height of potatoes per plant, $P=0.9022$ for the weight of potatoes per plant) nor 
changes in potato tuberization ( $\mathrm{P}=0.9397$ for the number of potato tubers per plant). Consequently, vegetative growth potentials were deemed similar in transgenic and non-transgenic lines.

\section{Discussion}

LEA protein family members present in the many parts of plant cells such as cytoplasm, near the cellular membrane nucleus, mitochondria, vacuoles, as well as in amyloplasts [47]. They are related to multiple stress-inducing regulatory genes like the Abscisic acid (ABA), which mediates the plant stress response by its cis-regulatory elements known as abscisic acid-responsive elements (ABREs). LEA proteins accumulate in plants during cold acclimation. They participate in cryoprotection mechanisms in the tissues where primary ice nucleation occurs. Also, LEA proteins protect lactate dehydrogenase activity in the cyclic frozen and unfrozen conditions. They support the enzyme in a circumstance like seed storage in low temperature and the soil during winter. In dehydrating seeds or throughout the plant, the LEA proteins can store the water molecules needed to catalyze biochemical reactions, especially in wintertime, and activate the enzymes in such dehydration conditions [47]. Recently, 12 LEA protein groups were characterized based on their motifs and a unique set of physicochemical properties. Hva1 is a member of the LEA3 group [48]. Hva1 can improve plant growth characteristics in terms of total dry mass, root fresh weight, and shoot dry weight in response to abiotic stress, which holds considerable potential for use as molecular tools for genetic crop improvement toward stress tolerance. It has been introduced successfully into numerous plants (Supplementary file 2).

Because of high transformation performance and relatively stable insertion, reduced copy number and co-suppression, constant expression, and frequent recovery of plants with normal phenotypes, Agrobacterium-mediated transformation is applied predominantly for gene transfer in not only dicot but also monocot plants [29]. There are numerous reports of the successful transformation of various potato cultivars such as Desiree, Atlantic, Mnandi, Daejima, Andigena, Jowon, and the American cultivar Russet Burbank (Table 2). The Agrobacterium-mediated transformation in the potato cultivars requires callusinducing somatic embryogenesis, which is faced by several barriers, particularly in the plant regeneration phase $(8,9,11,58-60)$. Low transformation frequency with $15 \%$ obtained with the potato cultivar Mnandi indicated that this cultivar is sensitive to transformation by this method [11]. Besides, in the Atlantic cultivar, a high frequency of regenerated plants showed in fresh leaf and stem explants $(71.7 \%$ for leaves and $20.5 \%$ for stems), although the frequency of transgenic plants was low ( $4.3 \%$ and $2.5 \%$ for leaves and stems respectively) because of somaclonal variation. In addition, there are reports that somaclonal variation detected in potato plants regenerated from petiole, leaf, tuber, stem, and protoplasts [61]. To obtaining a high number of transformed plants, parameters consist of Acetosyringone concentrations, Zeatin levels, NAA, and A. tumefaciens strains were examined on several cultivars, and only a specific combination of these parameters was successful for each genotype [11]. However, this method has many disadvantages, such as unwanted somaclonal variations and chromosomal aberrations [62]. In potatoes, the Agrobacterium-mediated transformations are in connection with callus-based somatic embryogenesis or shoot tip organogenesis $[8,9,11,58-60]$. Yet a few articles describing the Agrobacterium-mediated tissue culture-independent transformation method. In-planta is a new and efficient Agrobacterium- 
mediated tissue culture-independent transformational method, which is easy to apply. It does not require the tissue culture-based regeneration of transgenic and eliminates the chances of somaclonal variation, as induced during in vitro culture. Therefore, it can explore more plants. The method is cost-effective, fast, and more efficient in comparison tissue culture-based transformation and can open new gates for recalcitrant plants $[62,63]$. It can generate many transgenes in less time with the lowest cost, makes it more acceptable nowadays [62], and maybe explored in more plants well [37, 63].

The present study is the first report on a successful transformation of potato in-planta whereby Agrobacterium can direct at potato seed sprouts through injection, who develop the reproducible and transferable protocol for tissue culture-independent in-planta transformation successfully for potato cv. Agria. The stable gene transformation divides into two phases: First, the gene transfers to the potato cells and integration into the genome successfully. At this point, we used an innovative way to transform the structure into the Agria genome (Fig. 1). We can transfer the gene to the potato sprout cells with high efficiency but without the problems caused by tissue culture-dependent gene transferring. The driving force behind the transformation method are highly efficient, healthy, time consuming, coast effective, repeatable and high-throughput. This method is invaluable experience for functional genomic studies and crop improvement programs. We recorded a transformation efficiency of $46 \%$ by injecting Agrobacterium suspension into the potato sprouts. Here, the transformation efficiencies acquired were higher than those reported using tissue culture-based transformation approaches; $[11,27,61]$ (Supplementary file 3).

Also, the method evades tedious plant tissue culture procedures eliminate the chances of somaclonal variation induced during in vitro culture. Both PCR and comparative ELISA confirmed stable integration of the transgenes in the transgene tuber. ELISA properly demonstrated the stably transfer, transcription, and translation of the hva1 into the protein resulting a successful transformation of the gene by the genetic manipulation throughout culture-independent in-planta transformation regime. The results indicate successful integration of activation tagged-plasmid into the potato genome and producing the stably transformed potato lines. Besides, methylation of the transgene promoter or degradation of transcripts by a different cellular mechanism such as siRNA/miRNA mediated gene silencing may affect the transgene transcription [74]. However, in the transgene, the successful expression of hva1 and the product accumulation suggest the transgene transcription and translation. 35S-promoter from cauliflower mosaic virus is one of the influential general promoters leading to constitutively high transcript consequent in producing protein in senior levels of the transgene far from environmental conditions or tissue types [75]. Our observation revealed the developmental morphology in the transplants same as what that observed in non-transgenic ones. The amplification of the transgene in the transgene produced tubers supporting transgene expression in the next vegetative generation. Besides, the results demonstrate the Acetosyringone's role in the transformation. Acetosyringone was important factor affecting the DNA delivery and transformation efficiency. It discussed that Acetosyringone carries out a key role in enhancing the activity of virgenes of the Agrobacterium, which can facilitate the initial processing of the T-DNA region in transferring from the Agrobacterium [76]. However, Agrobacterium strain and its plasmid and chromosomal genome affecting the plant cell attachment and plasmid transmission playing key role 
in the plant in-planta transformation. Agrobacterium C58 contain the modified pBI121 binary hypervirulent Ti-plasmid conferring high transformation efficiencies.

The evidence in the present study revealed that overexpression of hva1 in the stably integrated genetic material in the potato genome alleviated the freezing and chilling damages. Dehydration is a chief component of freezing stress. Hva1 product belongs to a class of proteins called hydrophilic. It has the function of cell production from damages caused by water limitation. In our study, a key feature is the improved freezing and chilling tolerance in hva 1-overexpressing lines of the potato displaying greater survivability. Therefore, our proposed procedure adopts recalcitrated cultivars like Agria that cannot produce enough vigorous shoots in tissue culture. It can consider as a transformation technique, which is less expensive and more efficient than previous methods used for the Agria cultivar. It is also possible to use the hva 1 gene transformation in improving the chilling and freezing stress in the other Solanaceae species.

In the second phase, we used a different system to select the transformed shoots using the EPSPS as a marker to discriminate transformants from non-transformants instead of the commonly used antibiotic resistance gene. In addition to the usefulness of easy selection of the transformants from nontransformants, it provides a possibility that two beneficial genes are simultaneous transfer to the plant. Concurrent overexpression of hva 1 and EPSPS displays the freezing tolerance and weed control in the potatoes. In such conditions, glyphosate binds to the encoded EPSPS enzyme and blocks the biosynthesis of 5-enolpyruvyl-shikimate-3-phosphate. Thereby it starves plants of essential amino acids and secondary metabolites. EPSPS affinity for PEP is much higher than for glyphosate, so the EPSPS protein preferentially binds PEP, which is the basis for glyphosate tolerance in CP4 EPSPStransformed plants. In this respect, potato crops are particularly vulnerable to weed competition from emergence to canopy closure and are significant in terms of yield. Glyphosate is one of the broad-spectrum universal herbicides used to control weeds. There are numerous reports about the transformation of the EPSPS gene into the potato. To exhibiting resistance against Colorado potato beetle, glyphosate, and Potato Leaf Roll Virus, Monsanto ${ }^{\circledR}$ develops New Leaf ${ }^{\mathrm{TM}}$ Plus Russet Burbank potatoes (RMBT-33,4 transformation events), which expressing cry3A, CP4-EPSPS, plrv_orf1, and plrv_orf2 genes simultaneously [28]. Transgenic potato lines expressing CP4 EPSP synthase exhibit resistance against glyphosate [24]. Freeze tolerance improved by overexpression of $h v a 1$ in potatoes. It was evident in the form of a higher percentage of survivability. It could show how hva 1 can improve plant survival under freezing temperatures in other Solanaceae species as well. This method gives new hope to improve the most economical crop species. Further improvement in the optimization of this method to beneficial effects in many crops is required.

\section{Conclusion}

The potato varieties are highly heterozygous and recalcitrant plants to regeneration in Agrobacteriummediated tissue culture-dependent transformation. To overcome the limitations, we introduce the innovative Agrobacterium-mediated tissue culture-independent transformation in-planta protocol for hva 1 
and EPSPS simultaneous transform by direct injection of the Agrobacterium cell pellet in autoclaved MS medium suspension into potato tuber sprouts. The gene integration into the potato genome and their overexpression in the transplants confirmed by competitive PCR reaction, Reverse Transcriptase PCR (RTPCR), and Enzyme-Linked Immunosorbent Assay (ELISA). The evidence revealed the overexpression of hva 1 and EPSPS in the stably integrated genetic material in the potato genome and its alleviation in the freezing and chilling damages and glyphosate tolerance simultaneously. These lines could be used as a source of germplasm for efficient potato breeding programs. As well, it could show how hva1 can improve plant survival under freezing temperatures in other Solanaceae species. However, further studies are required to determine their agricultural potential under field conditions.

\section{Abbreviations}

LEA: late embryogenesis abundant; HVA1: Hordeum vulgaris abundant protein gene; EPSPS. 5enolpyruvylshikimate-3-phosphate synthase; PCR: Polymerase Chain Reaction; RT-PCR: Reverse Transcriptase PCR; ELISA: enzyme-linked immunosorbent assay.

\section{Declarations}

\section{Authors' information}

${ }^{1}$ Department of Plant Breeding and Biotechnology, Faculty of Agriculture, University of Zabol, Zabol, IRAN.

2 Institute of Biotechnology, School of Agriculture, Shiraz University, Shiraz, IRAN.

\section{Ethics approval and consent to participate}

Not applicable.

\section{Consent to publish}

Not applicable.

\section{Availability of data and materials}

The datasets during and/or analysed during the current study are included in this published article and its supplementary information files or are available from the corresponding authors on reasonable request.

\section{Competing interests}

The authors declare that they have no competing interests.

\section{Funding}


This investigation was supported by a research grant (UOZ-GR -9618-33) for in writing the manuscript provided by the University of Zabol.

\section{Authors' Contributions}

All authors have contributed to carry out this research. D.Ch: Investigation, Data curation, Writing original draft. N. M. N: Conceptualization, Methodology, Validation, Investigation, Writing - original draft, Writing - review \& editing, Visualization. A. N: Resources, Methodology, Validation, Writing - original draft, Supervision, Project administration. B. A. F: Validation, Methodology, Investigation, Writing - original draft. A.A. E: Resources, Investigation, Writing - original draft, Writing - review \& editing. All authors read and approved the final manuscript.

\section{Acknowledgements}

The authors appreciate the contributions of the Institute of Biotechnology of the Shiraz University for providing genetic materials, scientific and financial supports. Also, this investigation was supported by the University of Zabol.

\section{References}

1. http:// [Internet]. 2018.

2. Molla M, Nasiruddin K, Al-Amin M, Haque M. Agrobacterium-mediated transformation in potato. Thai Journal of Agricultural Science. 2011;44(2):93-102.

3. Reddy B, Mandal R, Chakroborty M, Hijam L, Dutta P. A review on potato (Solanum tuberosum L.) and its genetic diversity. International Journal of Genetics, ISSN. 2018:0975-2862.

4. Beals KA. Potatoes, nutrition and health. Am J Potato Res. 2019;96(2):102-10.

5. Watanabe K. Potato genetics, genomics, and applications. Breeding science. 2015;65(1):53-68.

6. Levy D, Veilleux RE. Adaptation of potato to high temperatures and salinity-a review. Am J Potato Res. 2007;84(6):487-506.

7. Romano A, Raemakers K, Visser R, Mooibroek H. Transformation of potato (Solanum tuberosum) using particle bombardment. Plant Cell Rep. 2001;20(3):198-204.

8. Chakravarty B, Wang-Pruski G, Flinn B, Gustafson V, Regan S. Genetic transformation in potato: approaches and strategies. Am J Potato Res. 2007;84(4):301-11.

9. Craze M, Bates R, Bowden S, Wallington EJ. Highly Efficient Agrobacterium-Mediated Transformation of Potato (Solanum tuberosum) and Production of Transgenic Microtubers. Current protocols in plant biology. 2018;3(1):33-41.

10. Hussain I, Rashid H, Muhammad A, Ali K, Asghar R, Naqvi S, et al. Introduction of rice chitinase gene in potato by Agrobacterium-mediated transformation. Pakistan Journal of Agricultural Sciences. 2019;56(1). 
11. Veale M, Slabbert M, Van Emmenes L. Agrobacterium-mediated transformation of potato cv. Mnandi for resistance to the potato tuber moth (Phthorimaea operculella). South African Journal of Botany. 2012;80:67-74.

12. Babu RC, Nguyen BD, Chamarerk V, Shanmugasundaram P, Chezhian P, Jeyaprakash P, et al. Genetic analysis of drought resistance in rice by molecular markers: association between secondary traits and field performance. Crop Sci. 2003;43(4):1457-69.

13. Checker VG, Chhibbar AK, Khurana P. Stress-inducible expression of barley Hva1 gene in transgenic mulberry displays enhanced tolerance against drought, salinity and cold stress. Transgenic research. 2012;21(5):939-57.

14. Duan J, Cai W. OsLEA3-2, an abiotic stress induced gene of rice plays a key role in salt and drought tolerance. PLoS One. 2012;7(9):e45117.

15. Sivamani E, Bahieldin A, Wraith JM, Al-Niemi T, Dyer WE, Ho T-HD, et al. Improved biomass productivity and water use efficiency under water deficit conditions in transgenic wheat constitutively expressing the barley HVA1 gene. Plant science. 2000;155(1):1-9.

16. Yao X, Wu K, Yao Y, Li J, Ren Y, Chi D. The response mechanism of the HVA1 gene in hulless barley under drought stress. Italian Journal of Agronomy. 2017;12(4).

17. Dure L, Chlan C. Developmental biochemistry of cottonseed embryogenesis and germination: XII. Purification and properties of principal storage proteins. Plant Physiol. 1981;68(1):180-6.

18. Bray EA. Plant responses to water deficit. Trends in plant science. 1997;2(2):48-54.

19. Ingram J, Bartels D. The molecular basis of dehydration tolerance in plants. Annu Rev Plant Biol. 1996;47(1):377-403.

20. Thomashow MF. Role of cold-responsive genes in plant freezing tolerance. Plant physiology. 1998;118(1):1-8.

21. Khan S, Anwar S, Yu S, Sun M, Yang Z, Gao Z-q. Development of drought-tolerant transgenic wheat: achievements and limitations. Int J Mol Sci. 2019;20(13):3350.

22. Xu D, Duan X, Wang B, Hong B, Ho T-HD, Wu R. Expression of a late embryogenesis abundant protein gene, HVA1, from barley confers tolerance to water deficit and salt stress in transgenic rice. Plant physiology. 1996;110(1):249-57.

23. Straub PF, Shen Q, Ho T-hD. Structure and promoter analysis of an ABA-and stress-regulated barley gene, HVA1. Plant molecular biology. 1994;26(2):617-30.

24. Bakhsh A, Hussain T, Rahamkulov I, Demirel U, Çalışkan ME. Transgenic potato lines expressing CP4EPSP synthase exhibit resistance against glyphosate. Plant Cell Tissue Organ Cult. 2020;140(1):2334.

25. Brookes G, Barfoot P. Economic impact of GM crops: the global income and production effects 1996-2012. GM crops food. 2014;5(1):65-75.

26. Dill GM. Glyphosate-resistant crops: history, status and future. Pest Management Science: formerly Pesticide Science. 2005;61(3):219-24. 
27. Bakhsh A. Development of efficient, reproducible and stable Agrobacterium-mediated genetic transformation of five potato cultivars. Food Technology Biotechnology. 2020;58(1):57.

28. ISAAA. https://www.isaaa.org/gmapprovaldatabase/event/default.asp?EventID=204. 2019.

29. Kalbande BB, Patil AS. Plant tissue culture independent Agrobacterium tumefaciens mediated Inplanta transformation strategy for upland cotton (Gossypium hirsutum). Journal of Genetic Engineering Biotechnology. 2016;14(1):9-18.

30. Bairu MW, Kane ME. Physiological and developmental problems encountered by in vitro cultured plants. Plant Growth Regul. 2011;63(2):101-3.

31. Feldmann KA, Marks MD. Agrobacterium-mediated transformation of germinating seeds of Arabidopsis thaliana: a non-tissue culture approach. Molecular General Genetics MGG. 1987;208(1):1-9.

32. Jan SA, Shinwari ZK, Shah SH, Shahzad A, Zia MA, Ahmad N. In-planta transformation: Recent advances. Romanian Biotechnological Letters. 2016;21(1):11085-91.

33. Niazian M, Noori SS, Galuszka P, Mortazavian SMM. Tissue culture-based Agrobacterium-mediated and in planta transformation methods. Soil Water Research. 2017;53(4):133-43.

34. Supartana P, Shimizu T, Nogawa M, Shioiri H, Nakajima T, Haramoto N, et al. Development of simple and efficient in planta transformation method for wheat (Triticum aestivum L.) using Agrobacterium tumefaciens. Journal of bioscience bioengineering. 2006;102(3):162-70.

35. Mayavan S, Subramanyam K, Arun M, Rajesh M, Dev GK, Sivanandhan G, et al. Agrobacterium tumefaciens-mediated in planta seed transformation strategy in sugarcane. Plant cell reports. 2013;32(10):1557-74.

36. Abhishek A, Kumari R, Karjagi CG, Kumar P, Kumar B, Dass S, et al. Tissue culture independent Agrobacterium tumefaciens mediated in planta transformation method for tropical maize (Zea mays. L). Proceedings of the National Academy of Sciences, India Section B: Biological Sciences. 2016;86(2):375 - 84.

37. Katavic V, Haughn GW, Reed D, Martin M, Kunst L. In planta transformation of Arabidopsis thaliana. Molecular General Genetics MGG. 1994;245(3):363-70.

38. Ratanasut K, Rod-In W, Sujipuli K. In planta Agrobacterium-mediated transformation of rice. Rice Sci. 2017;24(3):181-6.

39. Yasmeen A, Mirza B, Inayatullah S, Safdar N, Jamil M, Ali S, et al. In planta transformation of tomato. Plant molecular biology reporter. 2009;27(1):20-8.

40. Yellisetty V, Reddy L, Mandapaka M. In planta transformation of sorghum (Sorghum bicolor (L.) Moench) using TPS1 gene for enhancing tolerance to abiotic stresses. Journal of genetics. 2015;94(3):425-34.

41. Karthik S, Pavan G, Sathish S, Siva R, Kumar PS, Manickavasagam M. Genotype-independent and enhanced in planta Agrobacterium tumefaciens-mediated genetic transformation of peanut [Arachis hypogaea (L.)]. 3 Biotech. 2018;8(4):1-15. 
42. Demirel U, Morris WL, Ducreux LJ, Yavuz C, Asim A, Tindas I, et al. Physiological, Biochemical, and Transcriptional Responses to Single and Combined Abiotic Stress in Stress-Tolerant and StressSensitive Potato Genotypes. Frontiers in plant science. 2020;11:169.

43. Stegner M, Schäfernolte T, Neuner G. New insights in potato leaf freezing by Infrared Thermography. Applied Sciences. 2019;9(5):819.

44. Kaiser WJ. Use of thermotherapy to free potato tubers of alfalfa mosaic, potato leaf roll and tomato black ring viruses. Phytopathology. 1980;70(11):1119-22.

45. Gawel N, Jarret R. A modified CTAB DNA extraction procedure forMusa andlpomoea. Plant Molecular Biology Reporter. 1991;9(3):262-6.

46. Kruger NJ. The Bradford method for protein quantitation. The protein protocols handbook. 2009:1724.

47. Kalemba E, Pukacka S. Possible roles of LEA proteins and SHSPs in seed protection: a short review. Biol Lett. 2007;44:3-16.

48. Jaspard E, Macherel D, Hunault G. Computational and statistical analyses of amino acid usage and physico-chemical properties of the twelve late embryogenesis abundant protein classes. PloS one. 2012;7(5):e36968.

49. Maqbool S, Zhong H, El-Maghraby Y, Ahmad A, Chai B, Wang W, et al. Competence of oat (Avena sativa L.) shoot apical meristems for integrative transformation, inherited expression, and osmotic tolerance of transgenic lines containing hva1. Theor Appl Genet. 2002;105(2-3):201-8.

50. Patnaik D, Khurana P. Genetic transformation of Indian bread (T. aestivum) and pasta (T. durum) wheat by particle bombardment of mature embryo-derived calli. BMC Plant Biol. 2003;3(1):1-11.

51. Bahieldin A, Mahfouz HT, Eissa HF, Saleh OM, Ramadan AM, Ahmed IA, et al. Field evaluation of transgenic wheat plants stably expressing the HVA1 gene for drought tolerance. Physiol Plant. 2005;123(4):421-7.

52. Oraby HF, Ransom CB, Kravchenko AN, Sticklen MB. Barley HVA1 gene confers salt tolerance in R3 transgenic oat. Crop Sci. 2005;45(6):2218-27.

53. Fu D, Huang B, Xiao Y, Muthukrishnan S, Liang GH. Overexpression of barley hva1 gene in creeping bentgrass for improving drought tolerance. Plant cell reports. 2007;26(4):467-77.

54. Lal S, Gulyani V, Khurana P. Overexpression of HVA1 gene from barley generates tolerance to salinity and water stress in transgenic mulberry (Morus indica). Transgenic Res. 2008;17(4):651-63.

55. Koerniati S, Widhianata H, Jl Veteran M. Construction and Transformation of HVA1 Gene. Expression Vector into Indonesian Elite Rice Varieties. J Agro Biogen 2019(8):54-61.

56. Nguyen TX, Sticklen M. Barley HVA1 Gene Confers Drought and Salt Tolerance in Transgenic Maize Zea Mays L. Advances in Crop Science and Technology; 2013.

57. Refaat M, EL-Akkad T, Saleh SS, Abdelgawed B. Improvement Of Salt Tolerance To Transgenic Potato (Solanum tuberosum L.) By Abundant Protein (HVA1) Gene Transfer. Egyptian Journal of Genetics And Cytology. 2018;47(1). 
58. Banerjee AK, Prat S, Hannapel DJ. Efficient production of transgenic potato (S. tuberosum L. ssp. andigena) plants via Agrobacterium tumefaciens-mediated transformation. Plant Sci. 2006;170(4):732-8.

59. Beaujean A, Sangwan R, Lecardonnel A, Sangwan-Norreel B. Agrobacterium-mediated transformation of three economically important potato cultivars using sliced internodal explants: an efficient protocol of transformation. Journal of experimental Botany. 1998;49(326):1589-95.

60. Millam S. Agrobacterium-mediated transformation of potato. Transgenic Crops of the World: Springer; 2004. pp. 257-69.

61. Han E-H, Goo Y-M, Lee M-K, Lee S-W. An efficient transformation method for a potato (Solanum tuberosum L. var. Atlantic). Journal of Plant Biotechnology. 2015;42(2):77-82.

62. Saifi SK, PN, Tuteja R, et al. planta transformation: A smart way of crop improvement. Advancement in crop improvement techniques. Elsevier Inc.; 2020.

63. Hamada H, Linghu Q, Nagira Y, Miki R, Taoka N, Imai R. An in planta biolistic method for stable wheat transformation. Scientific reports. 2017;7(1):1-8.

64. Jeong M-J, Park S-C, Byun M-O. Improvement of salt tolerance in transgenic potato plants by glyceraldehyde-3 phosphate dehydrogenase gene transfer. Molecules \& Cells (Springer Science \& Business Media BV). 2001;12(2).

65. Celebi-Toprak F, Behnam B, Serrano G, Kasuga M, Yamaguchi-Shinozaki K, Naka H, et al. Tolerance to salt stress of the transgenic tetrasomic tetraploid potato, Solanum tuberosum cv. Desiree appears to be induced by the DREB1A gene and rd29A promoter of Arabidopsis thaliana. Breed Sci. 2005;55(3):311-9.

66. Behnam B, Kikuchi A, Celebi-Toprak F, Kasuga M, Yamaguchi-Shinozaki K, Watanabe KN. Arabidopsis rd29A:: DREB1A enhances freezing tolerance in transgenic potato. Plant cell reports. 2007;26(8):1275-82.

67. Pino MT, Skinner JS, Park EJ, Jeknić Z, Hayes PM, Thomashow MF, et al. Use of a stress inducible promoter to drive ectopic AtCBF expression improves potato freezing tolerance while minimizing negative effects on tuber yield. Plant Biotechnol J. 2007;5(5):591-604.

68. Goo Y-M, Kim T-W, Lee M-K, Lee S-W. Accumulation of PrLeg, a perilla legumin protein in potato tuber results in enhanced level of sulphur-containing amino acids. Comptes rendus biologies. 2013;336(9):433-9.

69. Dou H, Xv K, Meng Q, Li G, Yang X. Potato plants ectopically expressing A rabidopsis thaliana CBF 3 exhibit enhanced tolerance to high-temperature stress. Plant Cell Environ. 2015;38(1):61-72.

70. Goo Y-M, Han E-H, Jeong JC, Kwak S-S, Yu J, Kim Y-H, et al. Overexpression of the sweet potato IbOr gene results in the increased accumulation of carotenoid and confers tolerance to environmental stresses in transgenic potato. Comptes rendus biologies. 2015;338(1):12-20.

71. Moon S-J, Han S-Y, Kim D-Y, Yoon IS, Shin D, Byun M-O, et al. Ectopic expression of a hot pepper bZIPlike transcription factor in potato enhances drought tolerance without decreasing tuber yield. Plant molecular biology. 2015;89(4):421-31. 
72. Cho K-S, Han E-H, Kwak S-S, Cho J-H, Im J-S, Hong S-Y, et al. Expressing the sweet potato orange gene in transgenic potato improves drought tolerance and marketable tuber production. Comptes rendus biologies. 2016;339(5-6):207-13.

73. Mba'u YJ, Iriawati I, Faizal A. Transient transformation of potato plant (Solanum tuberosum L.) granola cultivar using syringe agroinfiltration. AGRIVITA, Journal of Agricultural Science. 2018;40(2):313-9.

74. Fagard M, Vaucheret H. Systemic silencing signal (s). Plant Gene Silencing. 2000:165 - 73.

75. De Buck S, Jacobs A, Van Montagu M, Depicker A. Agrobacterium tumefaciens transformation and cotransformation frequencies of Arabidopsis thaliana root explants and tobacco protoplasts. Molecular plant-microbe interactions. 1998;11(6):449-57.

76. Gelvin SB. Agrobacterium-mediated plant transformation: the biology behind the "gene-jockeying" tool. Microbiology molecular biology reviews. 2003;67(1):16-37.

\section{Figures}




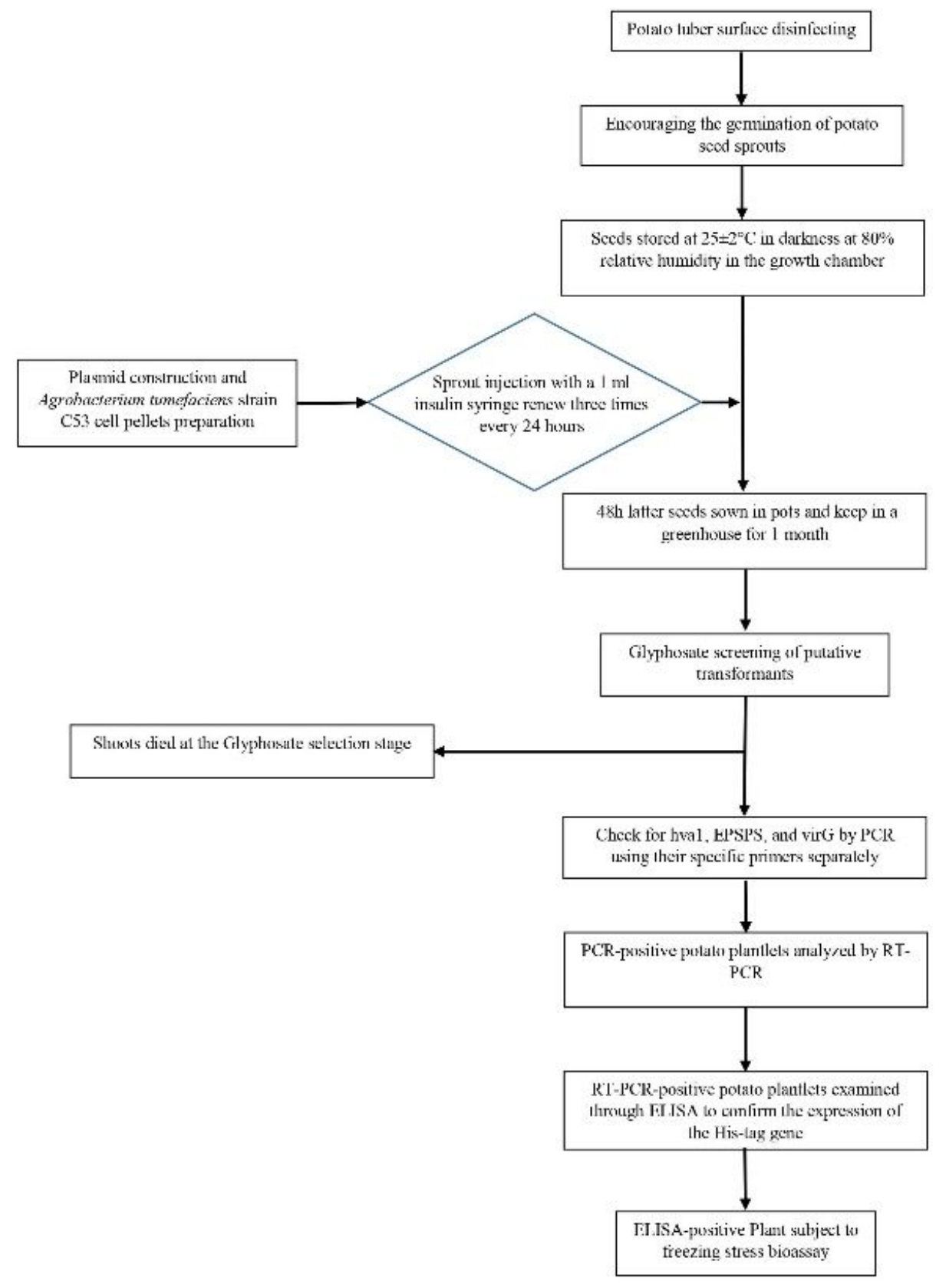

Figure 1

The schematic presentation of the main steps of in-planta stable gene transformation into Potato var. Agria genome. 


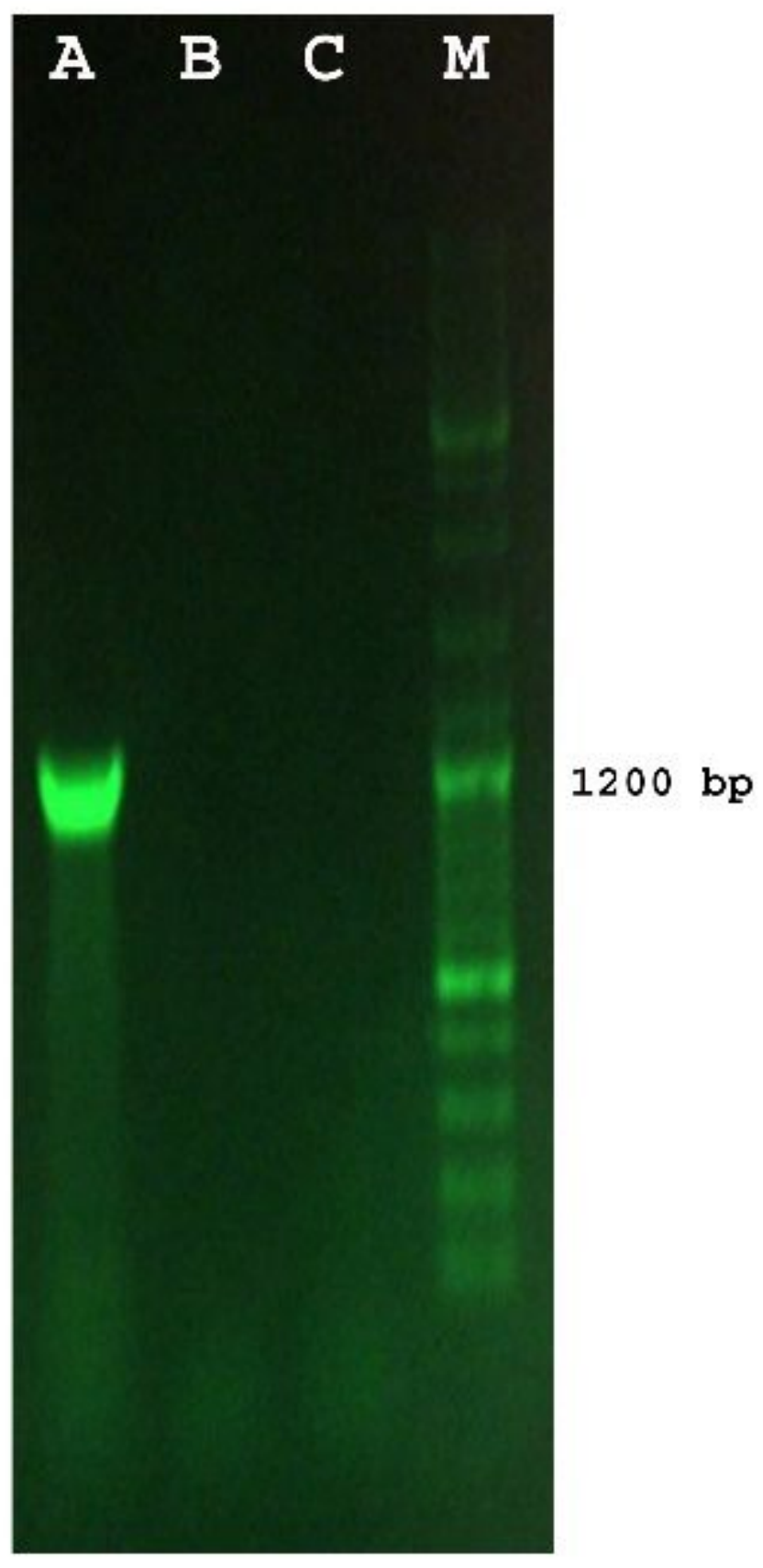

Figure 2

PCR product of the designed hva1 inserted in PUC57. The primers were amplified approximately 1200pb. The experiment was conducted to confirm the insertion of the structure to the PUC57 vector and cloning. M: 1000 bp DNA ladder, A: the structure inserted in PUC57, B: control reaction without the template, C: control group of non-inserted PUC57 plasmids. 


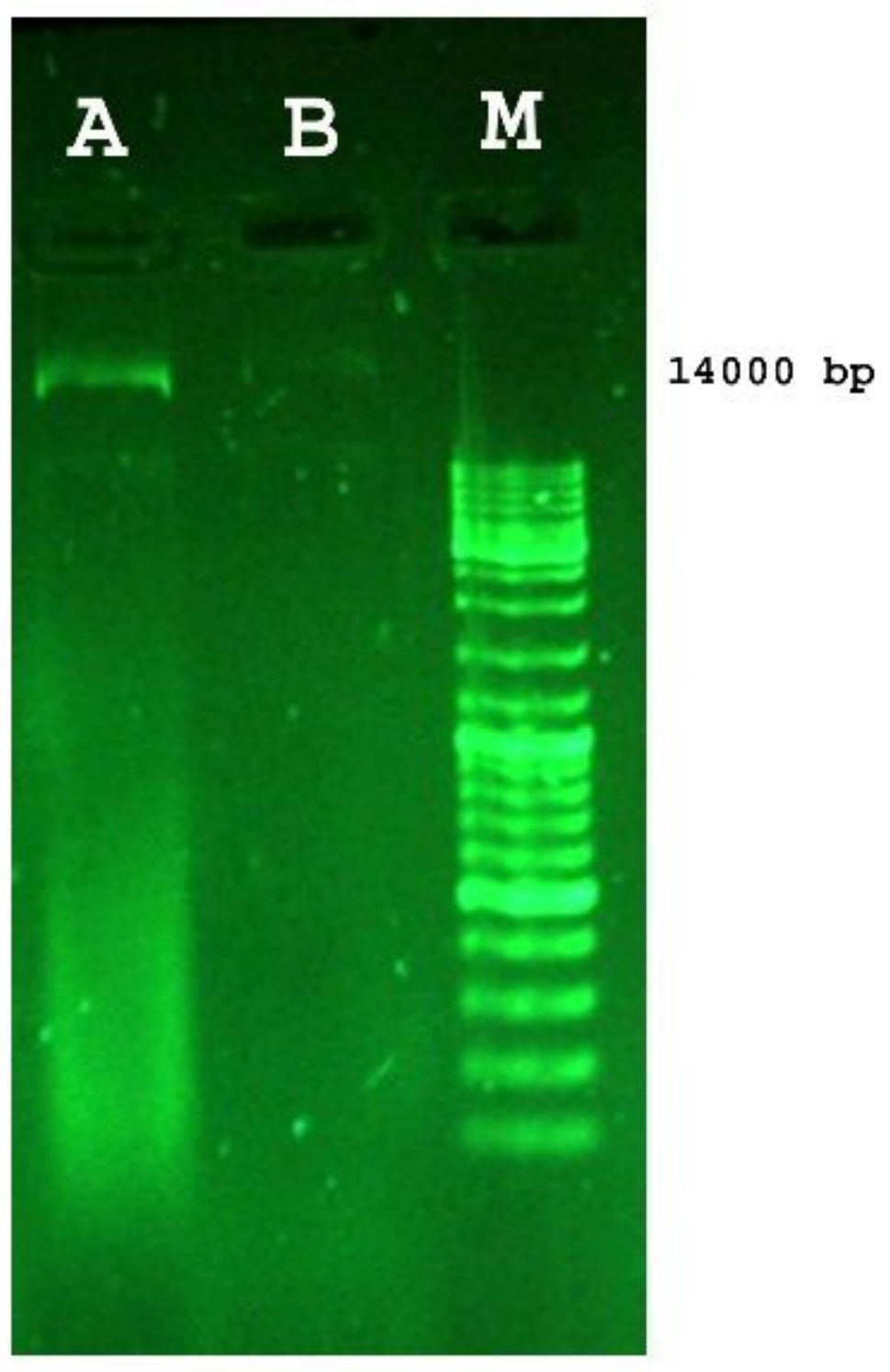

Figure 3

Extraction of cloned hva1-pBI121 vectors in E. coli. The hva1-pBI121 vector was cloned in E. coli after introducing it to the Agrobacterium tumefaciens C58. M: 1000bp DNA ladder, A: the binary vector hva1pBI121 was cloned by E. coli, B: the control (E. coli with no hva1-pBI121 vector). 

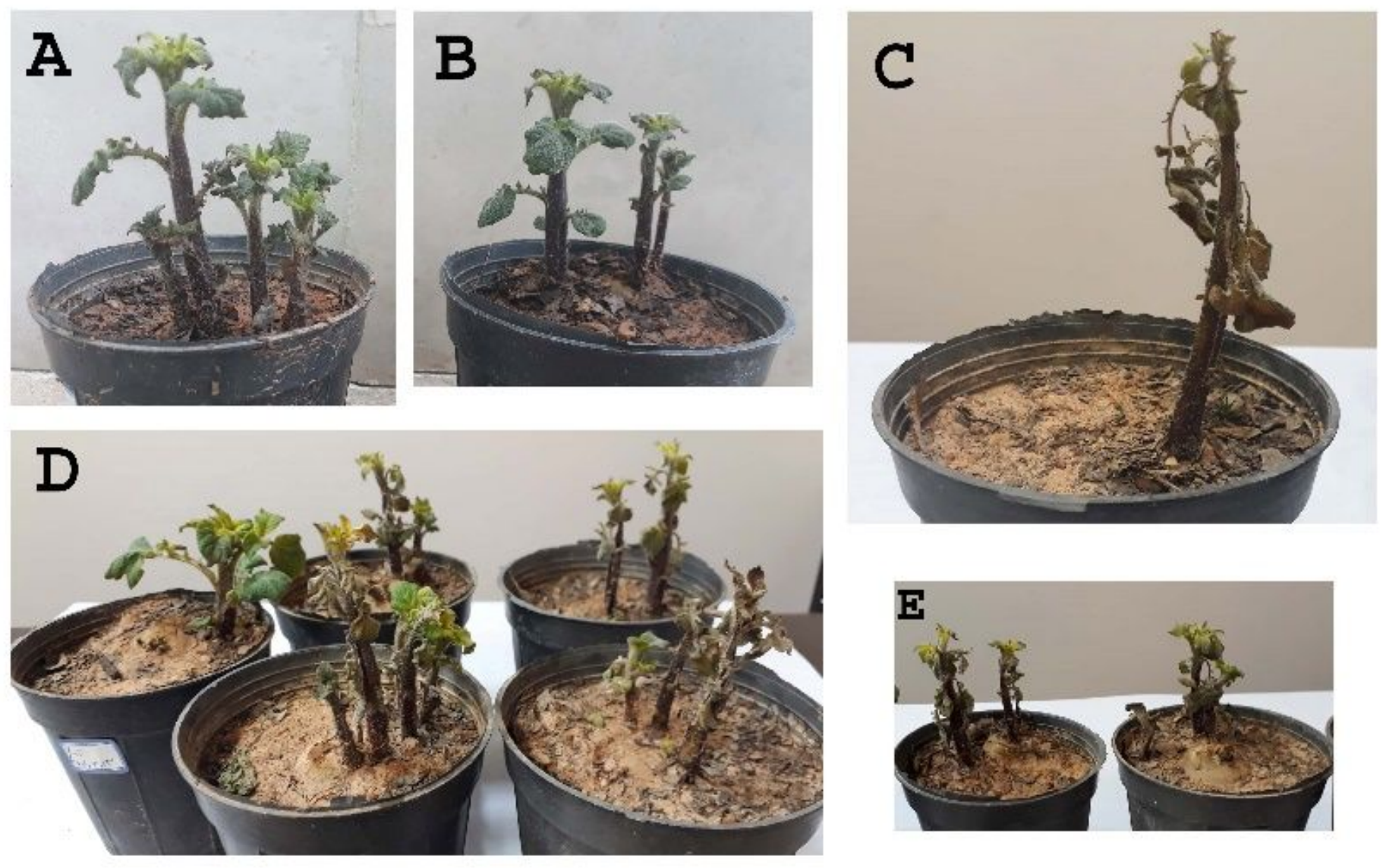

\section{Figure 4}

Glyphosate-treated potato plants. Transgenic Glyphosate-tolerant plants overproducing EPSPS survived at a high concentration of Glyphosate (2\%) after two weeks (A) in comparison with the non-Glyphosate control group (B) and non-screened sprout-treated plants that were treated by $0.5,1$ and $2 \%$ Glyphosate two weeks later (C). The symptoms of Glyphosate spearing on sprout-treated non-transgenic samples (D, E).

A

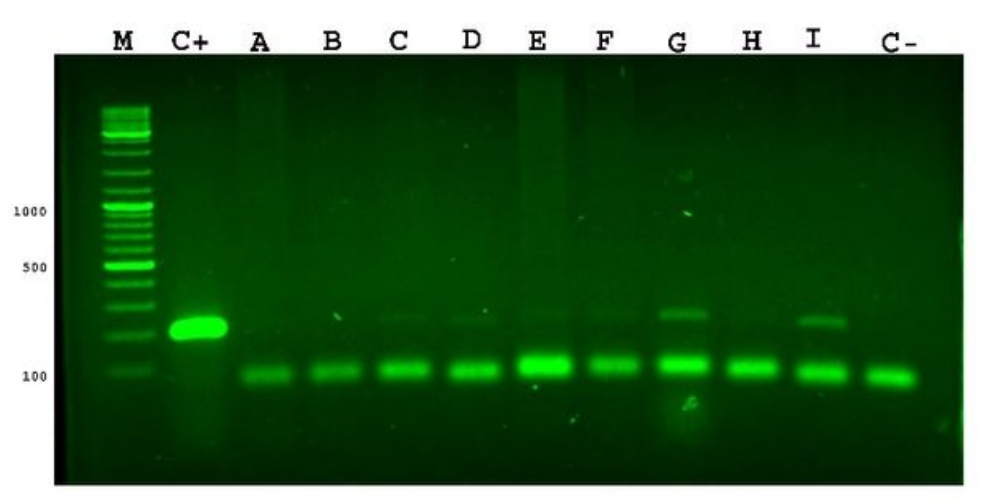

B

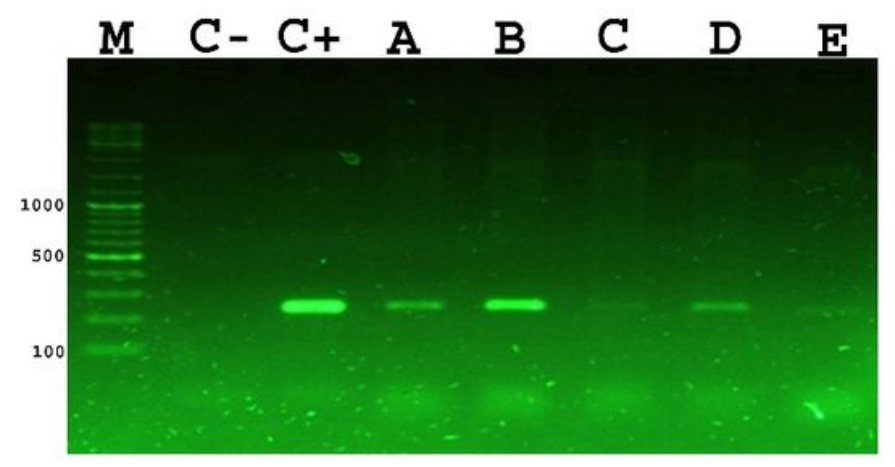

\section{Figure 5}


PCR analysis of DNA using the specific primers to detect the presence of the hva1 (A) and EPSPS (B) genes in the transgenic potatoes transformed by hva1-pBI121 showing the correct expected band sizes. Lane $\mathrm{C}+$ corresponds with the hva1-pBI121 positive control. Lane C-corresponds with non-transformed control potato. Lane M corresponds with $1 \mathrm{kbp}$ DNA ladder marker. Others represents transgenic plants from independent samples. The lower DNA bands in all the PCR reactions except the $\mathrm{C}+$ are dimer primers.

\section{$\mathrm{M} \mathrm{C}+\mathrm{A}$ B C-}

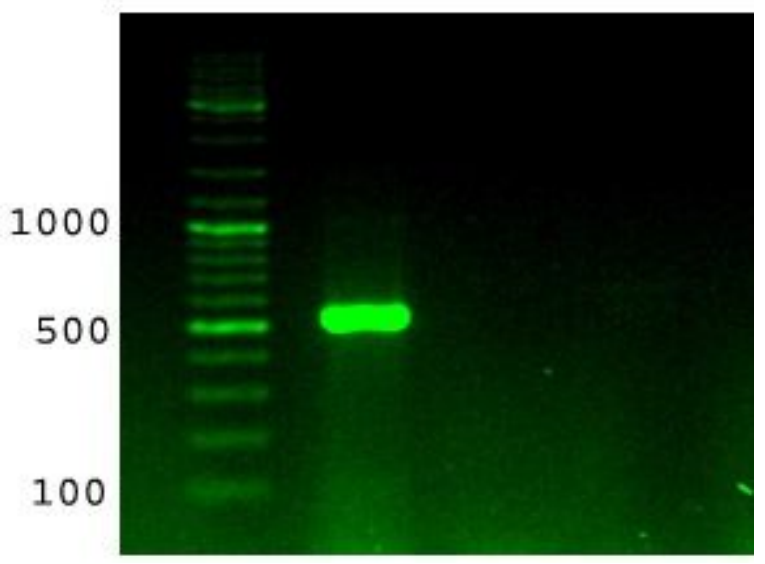

\section{Figure 6}

PCR analysis of the treated samples after one month using the specific primers to detect the presence of the virG to examine the contamination of the transformed samples with Agrobacterium. Lane C+: corresponds with the positive control. Lane C- corresponds with the negative control (non-transformed plant). Lane $\mathrm{M}$ corresponds with $1 \mathrm{kbp}$ DNA ladder marker. Lanes $\mathrm{A}$ and $\mathrm{B}$ represent transgenic plants from independent samples. 


\section{$\begin{array}{llllll}M & \text { C1 } & \text { A } & \text { B } & \text { D } & \text { C2 }\end{array}$}

500

200

\section{Figure 7}

The PCR reaction product of the hva1 genes in PCR-positive potato lines with the gene specific primer. Lane $\mathrm{C} 1$ represents PCR product from the full-length hva1 sequence as a positive control, Lan C2 represents PCR product from the non-transformed potato (a negative control), A, B and D lanes represent the PCR products from the produced cDNA from extracted RNA of independent transgenic samples. $M$ is the marker size. 


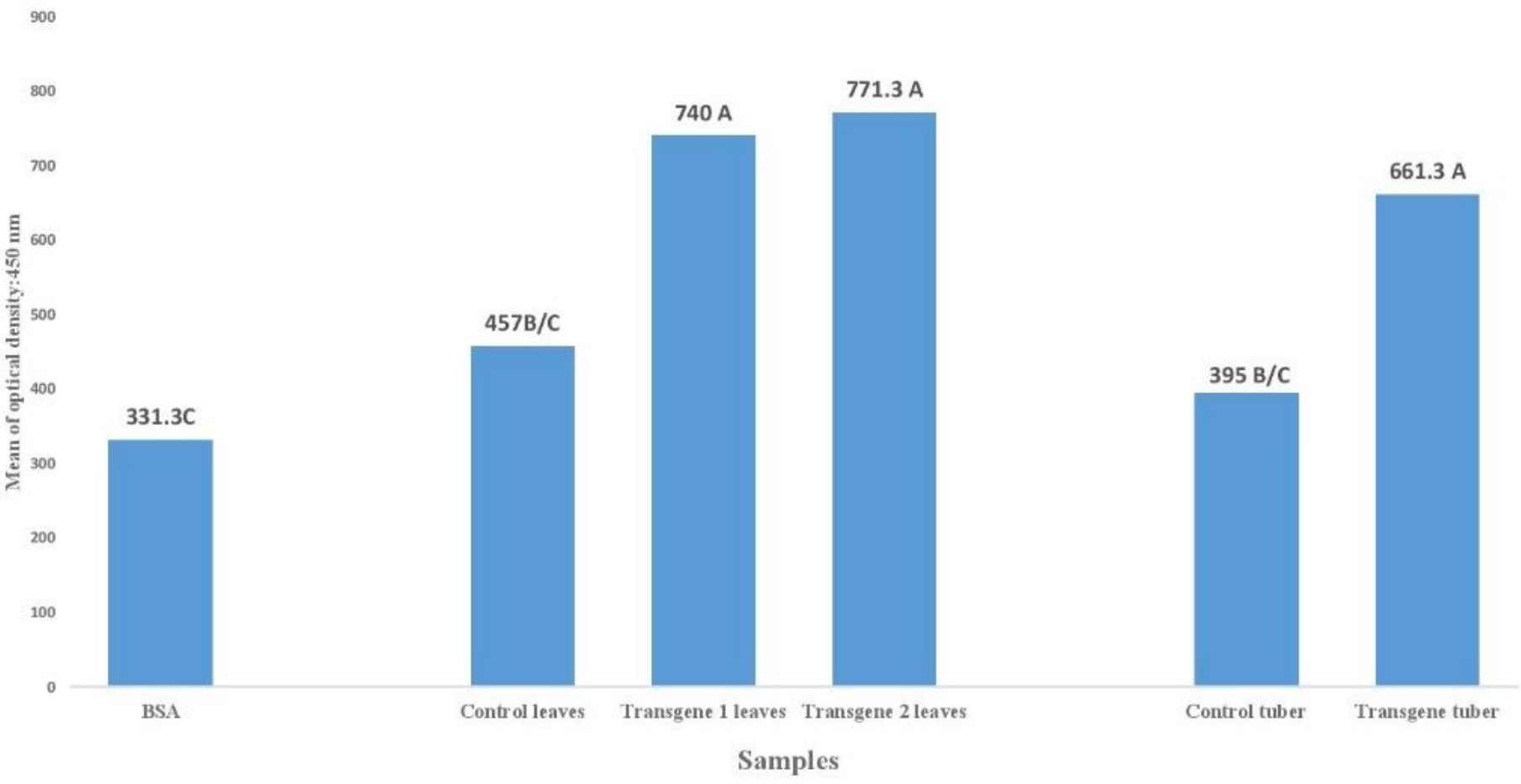

\section{Figure 8}

Analysis of His-tag protein expression in transgenic potato plants by comparative ELISA. OD values in $450 \mathrm{~nm}$ from transgenic potato plants, the transgene-generated tubers, BSA control and non-transformed control plants were analyzed in four replicates. The differences between the controls and the test samples were analyzed by one-way analysis of variance (ANOVAs) and Tukey's Multiple Comparison test $(P \leq 0.05)$. (Mean values that do not share a common letter are significantly different). 

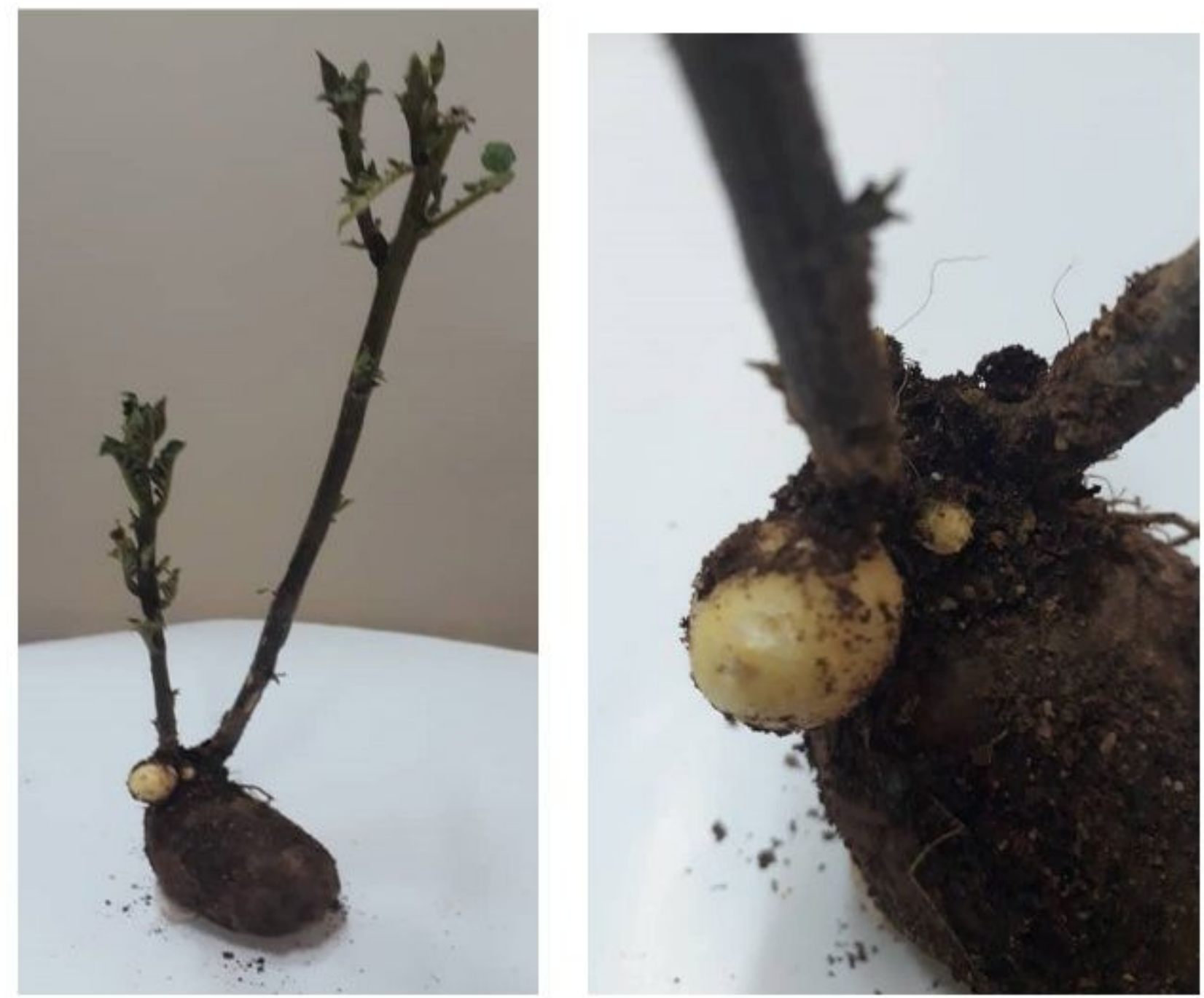

Figure 9

Tuberization of the transgene line from treated potato sprouts. The PCR- and ELISA-based results are indicative of a successful expression of hva1 and an accumulation of the hva1 protein in the transgenegenerated tuber.

\section{Supplementary Files}

This is a list of supplementary files associated with this preprint. Click to download.

- SupplementaryFile1.jpg

- Supplementaryfile2.docx

- Supplementaryfile3.docx

- supplementarypictures.docx 